\title{
AVALIAÇÃO DAS CONDIÇÕES HIGIÊNICO-SANITÁRIAS DOS QUIOSQUES INSTALADOS NA COMPANHIA DE ENTREPOSTOS E ARMAZÉNS GERAIS DO ESTADO DE SÃO PAULO (CEAGESP)
}

\author{
Fernanda Santos de Assis ${ }^{1}$, Cinthya Cristina Ugliara Vieira ${ }^{2}$, Bianca Assunção Iuliano ${ }^{3}$, \\ Eduardo Gonçalvez Rocha ${ }^{4}$, Fabiano Carrion Silva ${ }^{5}$, Fabiane Mendes da Câmara ${ }^{6}$, \\ Anita de Souza Dias Gutierrez ${ }^{7}$
}

\begin{abstract}
Mudanças no estilo de vida exigem alimentação fora do lar. No Brasil, são investidos cerca de 30\% da renda mensal neste setor. Na Companhia de Entreposto e Armazéns Gerais do Estado de São Paulo (CEAGESP) estão instalados 28 quiosques onde circulam aproximadamente 30 mil pessoas diariamente. É imprescindível a observação das condições higiênico-sanitárias desses locais, pois os alimentos oferecidos podem trazer malefícios à saúde do indivíduo. Objetivou-se avaliar as condições higiênico-sanitárias dos 28 quiosques e classificá-los em ÓTIMO, BOM, REGULAR e RUIM de acordo com o cumprimento dos itens estabelecidos na legislação vigente. Os dados foram coletados e analisados através de documentos e observação. Foram utilizadas as legislações: RDC 275; CVS 6 e 18 e SMS-G 1210, de âmbito federal, estadual (SP) e municipal (São Paulo), respectivamente, para análise da estrutura e higiene do local e práticas de manipulação. Observou-se que: 78\% dos quiosques obtiveram adequação REGULAR; inexistência de telas milimétricas nas janelas em 85,71\% dos quiosques e em 100\% dos quiosques ausência de material para higienização das mãos. Nenhum estabelecimento possuía termômetros nos refrigeradores ou nas estufas. Apenas 14,28\% das estufas apresentaram temperatura adequada no momento da observação. As condições higiênico-sanitárias dos quiosques são insatisfatórias, sendo necessárias mudanças comportamentais e estruturais, além de treinamentos e maior fiscalização.
\end{abstract}

Palavras-chave: vigilância sanitária, higiene dos alimentos, alimentação coletiva.

\footnotetext{
${ }^{1}$ Nutricionista. Correspondência: Rua Maria Madalena de Jesus, 45, Jd. das Margaridas, São Paulo, SP. CEP 06622-080. E-mail: fernandaassisnutri@gmail.com

${ }^{2}$ Médica Veterinária, Companhia de Entrepostos e Armazéns Gerais do Estado de São Paulo (CEAGESP).

${ }^{3}$ Nutricionista do Centro Universitário São Camilo.

${ }^{4}$ Nutricionista da CEAGESP.

${ }^{5}$ Médico Veterinário.

${ }^{6}$ Engenheira de Alimentos da CEAGESP e Mestranda em Ciência e Tecnologia de Alimentos, Escola Superior de Agricultura Luiz de Queiroz (ESALQ),

Universidade de São Paulo (USP), Piracicaba, SP.

${ }^{7}$ Engenheira Agrônoma, Dra. em Fitotecnia. CEAGESP.
} 


\section{EVALUATION OF THE HYGIENIC AND SANITARY CONDITIONS OF THE STANDS INSTALLED AT THE COMPANY OF GENERAL WAREHOUSES OF SÃO PAULO (CEAGESP)}

Changing lifestyle requires food away from home. In Brazil, approximately $24 \%$ of the monthly income is invested in this sector. At the CEAGESP there are 28 stands installed where approximately 30000 people circulate daily. It is imperative to observe the hygienic and sanitary conditions because the food offered by these stands may bring harm to people's health. The objective was to assess the hygienic and sanitary conditions of these stands and classify them into EXCELENT, GOOD, REGULAR and BAD in compliance with the items established in the laws in effective. Data were collected and analyzed through documents and observation. The current legislation was used and a checklist was created to analyze the structure, the local hygiene, and its handling practices. The majority (78\%) of the stands got a REGULAR adequacy assessment. There aren't any millimeter screens on the windows at $85.71 \%$ of the stands. There wasn't any material for hand hygiene at $100 \%$ of the stands. No establishment had thermometers in refrigerators or stoves and only $14.28 \%$ of the stoves had the proper temperature. The hygienic and sanitary conditions of the stands are unsatisfactory. A structural and attitudinal change as well as more training and greater scrutiny are absolutely necessary.

Key-words: sanitary surveillance, food hygiene, collective feeding.

\section{INTRODUÇÃO}

Devido a mudanças geradas no modo de vida urbano é necessário que o comensal se adapte as novas condições das quais dispõe, como tempo, recursos financeiros, locais disponíveis para se alimentar, local e periodicidade das compras, e outras. A indústria e o comércio oferecem alternativas que se adaptam às condições urbanas e apresentam novas modalidades no modo de comer, o que certamente contribui para mudanças no consumo alimentar ${ }^{[1]}$.

Fatores como extensa jornada de trabalho e a distância entre o domicílio e os locais de trabalho, impossibilitam um grande número de pessoas de realizar suas refeições regulares em família, utilizando estabelecimentos fixos ou distribuídos por ambulantes para a realização das refeições ${ }^{[2,3]}$. Este segmento tem crescido a cada dia. No Brasil estima-se que de cada cinco refeições, uma é feita fora de casa, na Europa duas em cada seis e, nos Estados Unidos, uma em cada duas ${ }^{[4]}$.

De acordo com a Pesquisa de Orçamento Familiar (POF) de 2008-2009 ${ }^{[5]}$, a população brasileira gasta cerca de $30 \%$ com alimentação fora do lar.

Corroborando com as informações citadas acima, nas dependências da Companhia deEntrepostos e Armazéns Gerais do Estado de São Paulo
(CEAGESP) estão instalados 28 quiosques servidores de alimentos onde circulam aproximadamente $30 \mathrm{mil}$ pessoas diariamente no local, que podem se alimentar nestes estabelecimentos.

Diante da crescente procura por esses serviços e a grande concorrência, ter qualidade é fundamental para todas as organizações. Entendese por qualidade aspectos intrínsecos ao alimento (qualidade nutricional e sensorial), à segurança (qualidade higiênico-sanitária), ao atendimento (relação cliente-fornecedor) e ao preço ${ }^{[4]}$.

Considerando esses aspectos, é imprescindível a observação das condições higiênico-sanitárias que esses locais possuem, uma vez que os alimentos servidos podem contribuir para a manutenção da saúde ou provocar malefício a ela, como uma Doença Transmitida por Alimentos (DTA) ${ }^{[3-6]}$. DTA são todas as complicações clínicas causadas por ingestão de perigos biológicos (alimentos contaminados com microorganismos patogênicos), químicos (substâncias tóxicas) ou físicos (objetos lesivos nos alimentos) ${ }^{[7]}$.

De acordo com informações presentes no site do Ministério da Saúde ${ }^{[8]}$, no período de 1999 a 2010 foram notificados 6.971 casos, com 1.804 .932 pessoas expostas, 133.954 doentes e registro de 88 óbitos. E este número pode ser ainda maior, visto que muitas vezes na ocorrência deste evento, não há 
procura médica e a DTA não é notificada.

São várias as formas de contaminação dos alimentos, por isso, deve-se monitorar todas as etapas do processo, como colheita, conservação, manipulação, transporte, armazenamento, preparo e distribuição ${ }^{[9]}$.

Uma das ferramentas usadas para a monitorização dessas etapas inclui as Boas Práticas de Fabricação (BPF), Procedimentos Operacionais Padronizados (POP) e o Sistema Análise de Perigos e Pontos Críticos de Controle (APPCC). Este último é o mais indicado pelos órgãos de fiscalização, pois é utilizado em toda cadeia produtiva de alimentos, e tem por objetivo a prevenção, racionalidade e especificidade para controle dos riscos que um alimento possa oferecer, principalmente no que diz respeito à qualidade sanitária, evitando possíveis eventos de DTA ${ }^{[10]}$.

Uma ferramenta comumente utilizada para verificação da monitorizarão das etapas descritas é o check list, que possibilita quantificar o grau de adequação de determinado estabelecimento de acordo com a legislação ${ }^{[4]}$.

Sendo assim, o objetivo do trabalho foi avaliar as condições higiênico-sanitárias dos quiosques distribuidores de refeições instalados na CEAGESP e classificá-lo de acordo com o cumprimento dos itens estabelecidos na legislação vigente.

\section{METODOLOGIA}

Trata-se de uma pesquisa de campo, descritiva de abordagem quantitativa [11], que ocorreu entre os meses de Junho a Setembro de 2009 com os 28 quiosques instalados na Companhia.

O levantamento das informações foi obtido através da utilização de impresso interno, fornecido pela empresa, contendo as seguintes informações: quantidade de quiosques existentes na companhia, localização deles, nome do responsável e área ocupada em metros quadrados (m2), observação dos quiosques e preenchimento de check list. Foi verificado também se os funcionários faziam algum tipo de controle de saúde através de conversas e verificação de documentos presentes no local.
Foi utilizado neste estudo o check list da RDC 275, de 21 de Outubro de $2002^{[12]}$.

Além dos 5 grupos presentes no check list (Edificações e Instalações; Equipamentos, Móveis e Utensilios; Manipuladores; Produção e Transporte dos Alimentos; Manual de Boas Práticas de Fabricação) utilizou-se também as legislações: Portaria do Centro de Vigilância Sanitária - CVS 6, de 10 de Março de 1999 [13]; Portaria CVS 18, de 9 de Setembro de $2008{ }^{[14]}$ e Portaria da Secretaria Municipal da Saúde - SMS-G no 1210, de 02 de agosto de $2006{ }^{[15]}$, para a criação de mais 6 grupos (Recebimento; Armazenamento de não perecíveis; Armazenamento de perecíveis; Pré-preparo; Preparo; Embalagem, Distribuição e Consumo).

O objetivo da criação desses grupos foi possibilitar questionamentos mais específicos sobre layout, fluxo adequado e periodicidade de limpeza tanto do local como dos equipamentos e usar parâmetros de tempo e temperatura que constam na legislação específica para a cidade de São Paulo, local onde foi realizada a pesquisa.

O check list presente na RDC no 275, de 21 de outubro de $2002^{[12]}$ apresenta três grupos de classificação de adequação em relação aos itens observados: GRUPO 1 - 76 a $100 \%$ de adequação; GRUPO 2 - 51 a $75 \%$ de adequação; GRUPO 3 - 0 a $50 \%$ de adequação. Para melhor especificidade e separação de diferentes situações, nesta pesquisa o grupo 3 foi desmembrado e criado um novo grupo. Os grupos receberam uma nova nomenclatura, a saber:

GRUPO 1 (ÓTIMO) - 76 a 100\% de adequação;

GRUPO 2 (BOM) - 51 a 75\% de adequação;

GRUPO 3 (REGULAR) - 26 a 50\% de adequação;

GRUPO 4 (RUIM) - 0 a 25\% adequação.

Dentro de cada eixo avaliado, foram observados aqueles com menores índices de adequação aos critérios estabelecidos no check list, para focar as ações de adequação mais imediatas.

No momento da entrevista foram ainda coletadas as temperaturas dos alimentos que necessitam deste tipo de controle com um termômetro infravermelho da marca Fluke ${ }^{\circledR}$, modelo 62. 
As informações obtidas foram tabuladas e agrupadas em um banco de dados utilizando o programa Microsoft Excel.

\section{RESULTADOS E DISCUSSÃO}

Todos os quiosques foram considerados na pesquisa e tiveram as informações tabuladas. De maneira geral todos os quiosques apresentaram falhas em relação a higiene, todos serviam mais de 100 refeições por dia, porém os mesmos só estavam autorizados a servir lanches. $\mathrm{O}$ tamanho em metros quadrados $\left(\mathrm{m}^{2}\right)$ de cada quiosque também variou bastante.

Após a tabulação e análise dos dados, os quiosques foram classificados nos grupos previamente estabelecidos (Tabela 1). Nenhum estabelecimento se enquadrou no grupo Ótimo de adequação aos itens observados e a grande maioria se enquadrou no grupo Regular, conforme mostrado a seguir.

Tabela 1. Distribuição dos quiosques segundo grupo de classificação de adequação. Companhia de Entrepostos e Armazéns Gerais do Estado de São Paulo (CEAGESP), São Paulo, 2009.

\begin{tabular}{cccc}
\hline Grupo & \% de adequação & $\mathrm{n}$ & $\mathbf{\%}$ \\
\hline Ótimo & 76 a 100 & 0 & 0 \\
Bom & 51 a 75 & 3 & 11 \\
Regular & 26 a 50 & 22 & 78 \\
Ruim & 0 a 25 & 3 & 11 \\
\hline Total & & 28 & 100 \\
\hline
\end{tabular}

Esse resultado deve-se a análise de vários quesitos presentes no check list, comparando-se com o que preconiza as legislações consideradas neste estudo e literatura específica do assunto, que será descrita de forma pormenorizada ao longo desse artigo.

Deve-se levar em consideração que o check list original ${ }^{[12]}$ possuía apenas 3 grupos, agrupando situações menos adequadas com outras mais adequadas.

\section{Edificações e instalações}

Foram tabulados os principais itens de edificações e instalações observados, como segue na tabela abaixo (Tabela 2), sendo que os mais preocupantes foram a inexistência de fechamento automático nas portas em todos os quiosques e de tela milimétrica nas janelas em $85,71 \%(n=24)$ dos mesmos, contrariando o que preconiza a Portaria 1210/2006 [15]. Segundo Veiga et al. apud Messias et al. ${ }^{[16]}$ as telas milimétricas evitam a entrada de pragas, como moscas e mosquitos nos estabelecimentos, que podem ser veículos de contaminação dos alimentos.

O espaço físico em metros quadrados $\left(\mathrm{m}^{2}\right) \mathrm{de}$ cada estabelecimento variou bastante. O menor quiosque possuía $6,20 \mathrm{~m}^{2}$ e o maior possuía $74,85 \mathrm{~m}^{2}$.

Tabela 2. Distribuição dos quiosques em relação à adequação de Edificações e Instalações. Companhia de Entrepostos e Armazéns Gerais do Estado de São Paulo (CEAGESP), São Paulo, 2009.

\begin{tabular}{lrrrr}
\hline \multirow{2}{*}{ Característica de Observação } & \multicolumn{4}{c}{ Adequação dos Quiosques } \\
\cline { 2 - 5 } & \multicolumn{3}{c}{ Sim } & \multicolumn{3}{c}{ Não } \\
\cline { 2 - 5 } & $n$ & $\%$ & $n$ & 53,57 \\
\hline Piso íntegro & 13 & 46,43 & 15 & 57,14 \\
Teto em adequado estado de conservação & 12 & 42,86 & 16 & 100,00 \\
Portas com fechamento automático & 0 & 0,00 & 28 & 85,71 \\
Janelas com telas & 4 & 14,29 & 24 & 60,71 \\
Luminária com proteção adequada & 11 & 39,29 & 17 & 96,43 \\
Layout adequado ao processo de acordo com o volume de produção & 1 & 3,57 & 27 & \\
\hline
\end{tabular}

De acordo com Silva Júnior ${ }^{[7]}$, o espaço físico deve permitir a fluência dentro do local evitando dúvidas quanto ao fluxo correto que aumenta o risco de contaminação cruzada. Deve-se ter uma área compatível com o fluxo do local. Para a determinação dessa área alguns itens são considerados, como número de refeições, diversificação do serviço, localização do estabelecimento e quantidade de equipamento. 
Observou-se que a dimensão e layout do ambiente não permitem fluência no interior do local (Tabela 2), evidenciando que as condições higiênicosanitárias destes estabelecimentos são fortemente prejudicadas pelo tamanho da estrutura física além dos aspectos anteriormente citados.

\section{Higiene dos Equipamentos e Móveis}

Segundo Hobbs \& Gilbert ${ }^{[17]}$, os alimentos podem ser contaminados pelo contato com utensílios, superfícies e equipamentos insuficientemente limpos. Em relação à higienização adequada das instalações, $71,43 \%(\mathrm{n}=20)$ dos quiosques não apresentavam equipamentos de fácil acesso e higienização, pois devido à pequena área para produção dos alimentos os equipamentos ficavam muito próximos uns dos outros dificultando a higienização, podendo favorecer assim a proliferação bacteriana e contaminação dos alimentos manipulados no local (Tabela 3).

No estudo de Oliveira et al. ${ }^{[18]}$, foi realizada análise microbiológica na máquina de moer carne e constatado que ela estava sendo fonte de contaminação da carne moída por falta de higienização. Já no estudo de Mendes et al. ${ }^{[19]}$ foram analisadas as bancadas de diferentes setores da Unidade de Alimentação e Nutrição (UAN) e encontrado Bacillus cereus em 27\% do total de amostras de bancadas analisadas.

Tabela 3. Adequação dos quiosques em relação à higiene das instalações. Companhia de Entrepostos e Armazéns Gerais do Estado de São Paulo (CEAGESP), São Paulo, 2009.

\begin{tabular}{|c|c|c|c|c|}
\hline \multirow[t]{2}{*}{ Características de observação } & \multicolumn{4}{|c|}{ Adequação dos Quiosques } \\
\hline & \multicolumn{2}{|c|}{ Sim } & \multicolumn{2}{|c|}{ Não } \\
\hline Móveis e equipamentos & $n$ & $\%$ & $n$ & $\%$ \\
\hline Fácil acesso e higienização * & 8 & 28,57 & 20 & 71,43 \\
\hline
\end{tabular}

* Material liso, impermeável, lavável, não de madeira.

Esses resultados se devem, na maioria dos casos, a acessibilidade insuficiente no local, deixando os equipamentos muito próximos uns dos outros.

Quanto aos produtos de limpeza, 71\% $(n=$ 21) dos quiosques não possuíam local próprio para guardá-los, deixando-os com outros produtos, como alimentos e embalagens, se contrapondo então ao que preconiza as legislações paulistanas, Portaria $1210 / 2006^{[15]}$ e CVS 06/1999 ${ }^{[13]}$.

\section{HIGIENE DOS MANIPULADORES}

Foi observado que nenhum estabelecimento possuía sabonete antisséptico para a higiene das mãos dos manipuladores e cartaz de orientação da lavagem correta das mãos, demonstrando falta de orientação para a correta higienização das mãos (Tabela 4), como preconiza a Portaria $1210^{[15]}$.
As mãos podem veicular grande carga bacteriana se não higienizadas adequadamente. Entre os microorganismos mais importantes para a ocorrência de DTA estão a Escherichia coli, indicador de contaminação fecal, Staphylococcus aureus, indicador de contaminação orofaríngeo e Bacillus cereus, indicador de contaminação ambiental. Esses microorganismos são considerados bons indicadores de má higiene, pois são erradicados após a correta higiene das mãos ${ }^{[7]}$.

A higienização inadequada das mãos pode permitir a presença desses patógenos, como ocorreu no estudo de Campos et al. ${ }^{[20]}$, no qual, dos quatro funcionários que trabalhavam com a fabricação de queijo, três apresentaram-se contaminados por Escherichia coli e, em 46 amostras obtidas a partir das mãos dos manipuladores investigados, foram isoladas oito cepas deste microorganismo. 
Tabela 4. Distribuição dos quiosques em relação aos manipuladores de alimentos. Companhia de Entrepostos e Armazéns Gerais do Estado de São Paulo (CEAGESP), São Paulo, 2009.

\begin{tabular}{|c|c|c|c|c|}
\hline \multirow{3}{*}{ Características de observação } & \multicolumn{4}{|c|}{ Quiosques adequados } \\
\hline & \multicolumn{2}{|c|}{ Sim } & \multicolumn{2}{|c|}{ Não } \\
\hline & $n$ & $\%$ & $n$ & $\%$ \\
\hline Uso de uniforme* & 25 & 89,29 & 3 & 10,71 \\
\hline Asseio pessoal & 13 & 46,43 & 15 & 53,57 \\
\hline Presença de POP** para higienização das mãos & 0 & 0 & 28 & 100,00 \\
\hline Presença de sabonete antisséptico & 0 & 0 & 28 & 100,00 \\
\hline Ausência de afecções cutâneas & 27 & 96,43 & 1 & 3,57 \\
\hline
\end{tabular}

*Avental e boné; ** Procedimento Operacional Padronizado.

Observa-se ainda na Tabela 4, que em 89,29\% $(n=25)$ dos estabelecimentos os funcionários consideravam somente avental e boné como uniformes e o restante não utilizava nenhum tipo de uniforme. A Resolução 216/2004 diz que os manipuladores devem utilizar uniforme compatível com a atividade, limpos e conservados e com troca diária ${ }^{[21]}$.

\section{PROGRAMA DE CONTROLE MÉDICO E SAÚDE OCUPACIONAL (PCMSO)}

A Norma Regulamentadora número 7 (NR7) trata do Programa de Controle Médico e Saúde
Ocupacional (PCMSO), um programa obrigatório que especifica quais os procedimentos a serem tomados conforme o grau de risco que o funcionário é exposto no ambiente de trabalho. Seu objetivo é a promoção e preservação da saúde de seus colaboradores ${ }^{[22]}$. Neste estudo foi observado (Tabela 5) que 46,43\% $(n=13)$ dos quiosques instalados na CEAGESP realizavam o programa, porém, apenas $23,08 \%(n=3)$ possuíam a documentação válida, ou seja, apresentava a documentação do PCMSO juntamente com os exames completos e na data vigente.

Tabela 5. Relação de quiosques que realizam o Programa de Controle Médico e Saúde Ocupacional (PCMSO). Companhia de Entrepostos e Armazéns Gerais do Estado de São Paulo (CEAGESP), São Paulo, 2009.

\begin{tabular}{lccccc}
\hline \multirow{2}{*}{ Características de observação } & \multicolumn{5}{c}{ Quiosques adequados } \\
\cline { 2 - 5 } & \multicolumn{3}{c}{ Sim } & \multicolumn{3}{c}{ Não } \\
\cline { 2 - 5 } & $n$ & $\%$ & 15 & 53,57 \\
\hline Realizam o Programa & 13 & 46,43 & 10 & 76,92 \\
Documentação válida & 3 & 23,08 & 10 & \\
\hline
\end{tabular}

Os funcionários não devem ser portadores aparentes ou inaparentes de doenças infecciosas ou parasitárias, sendo obrigatória à realização de exames médicos admissionais e periódicos ${ }^{[23]}$. A CVS 6, de $1999{ }^{[13]}$, descreve os exames laboratoriais que devem ser feitos pelos manipuladores (Hemograma, Coprocultura, Coproparasitológico e Veneral Disease Research Laboratory - VRDL), porém este item foi alterado pela Portaria CVS 18, de $2008{ }^{[14]}$ que não cita mais quais são os exames que devem ser feitos.

\section{TEMPERATURA DOS ALIMENTOS}

No Item Armazenamento de perecíveis, a Portaria $1210 / 2006{ }^{[15]}$ preconiza que os perecíveis sob refrigeração devem obedecer a limites de temperatura, a saber: Hortifrutis e outros produtos - até $10{ }^{\circ} \mathrm{C}$; Carne - até $4{ }^{\circ} \mathrm{C}$; e Pescado, até $2{ }^{\circ} \mathrm{C}$.

Porém, apenas um estabelecimento cumpria esses limites de temperatura, nenhum estabelecimento possuía termômetros nos refrigeradores, e, em geral, havia muitos produtos no equipamento, o que dificultava 
a circulação de ar frio, sobrecarregando o mesmo e não refrigerando adequadamente os produtos.

O autor Silva Júnior ${ }^{[7]}$ relata que a refrigeração deve ser feita em porções pequenas, com circulação de ar, em refrigerador com espaços adequados e bem regulados, diferentes da realidade da maioria dos quiosques visitados.

Para os alimentos prontos expostos para o consumo, em distribuição ou espera, também há estabelecido valores de temperatura que devem estar em conformidade com a Portaria 1210/2006 ${ }^{[15]}$ : Mínimo $60^{\circ} \mathrm{C}$, por no máximo por 6 (seis) horas de exposição; e Abaixo de $60^{\circ} \mathrm{C}$, por no máximo 1 (uma) hora de exposição.

Nestequesito, quatro (14,28\%) estabelecimentos estavam em conformidade. Foi considerado como "conformidade" para o estudo alimentos que estavam acima de $60{ }^{\circ} \mathrm{C}$, lembrando que no momento da visita os alimentos quentes muitas vezes já estavam expostos nas estufas e que a duração média da inspeção era de aproximadamente 30 minutos. Nenhuma estufa possuía termômetros e não há controle de tempo e temperatura dos alimentos prontos em nenhum dos estabelecimentos. Esse resultado se aproxima ao de Rosa et al. ${ }^{[24]}$, no qual 100\% das escolas das regiões Leste e Sul da cidade de Natal apresentaram temperaturas inadequadas no início e no final da distribuição dos alimentos.

No estudo de Lucca \& Torres ${ }^{[25]}$, os produtos cárneos e o purê de batatas da banca de cachorroquente comercializado na rua permaneciam em temperatura e em tempo de espera que propiciavam o crescimento bacteriano, semelhante a realidade dos estabelecimentos deste estudo.

\section{CONTROLE DE PRAGAS}

O Controle Integrado de Pragas (CIP) é indispensável nos serviços de alimentação, pois este ambiente comumente oferece os três elementos facilitadores para o desenvolvimento das pragas urbanas: alimento, abrigo éágua ${ }^{[7]}$. Osestabelecimentos devem contratar empresa especializada neste serviço [15] e manter no local o certificado ou comprovante de execução do serviço que pode ser solicitado pela autoridade sanitária municipal. As empresas dedetizadoras devem discriminar o prazo de garantia dos serviços prestados dependente da avaliação técnica, efetuada pela empresa ${ }^{[26]}$.

Foi observado que a metade $(n=14)$ dos quiosques estava em conformidade com a legislação apresentando certificado visível e com a data de validade vigente, demonstrando que há preocupação por parte do proprietário em impedir a instalação e proliferação de pragas urbanas.

Quanto aos outros quiosques, 35,71\% ( $n$ $=10)$ apresentavam o certificado, porém vencido ou sem data de vencimento e 14,29\% $(n=4)$ não apresentavam certificado no local no momento da visita (Figura 1).

Esses resultados são preocupantes, pois as ruas da CEAGESP comumente apresentam grande quantidade de lixo, o que já favorece a circulação de roedores, insetos e etc. e, em contrapartida, como já foi dito anteriormente poucos são os quiosques que possuem proteção contra essas pragas como telas milimétricas, aumentando a importância do CIP nestes estabelecimentos.

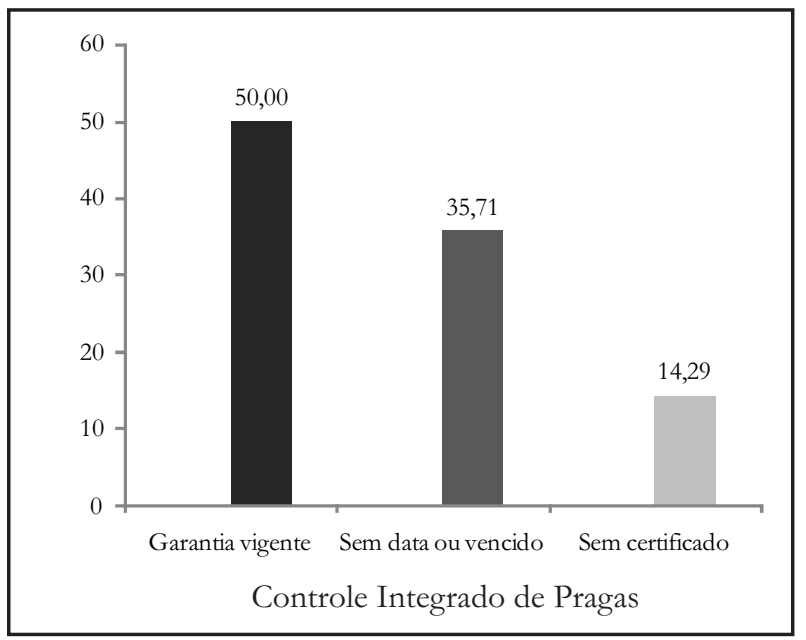

Figura 1. Distribuição percentual dos quiosques em relação ao Controle Integrado de Pragas. Companhia de Entrepostos e Armazéns Gerais do Estado de São Paulo (CEAGESP), São Paulo, 2009. 


\section{CONCLUSÃO}

As condições higiênico-sanitárias dos quiosques instalados na CEAGESP são bastante preocupantes, uma vez que quesitos mínimos para a garantia da qualidade do alimento não são seguidos nestes estabelecimentos.

Devido ao grande número de pessoas que realizam sua alimentação fora do lar, especificamente as que se alimentam em estabelecimentos como os quiosques, fast foods e comércio ambulante de alimentos, é necessário por parte dos órgãos que tratam sobre a segurança do alimento a regularização desses comerciantes, oferecimento de treinamentos em segurança dos alimentos e fiscalização dos mesmos. É importante também a criação de normas específicas para esse grupo de trabalhadores.

É necessário mais empenho por parte dos proprietários dos quiosques instalados na CEAGESP, visto que muitas não conformidades são evitáveis como o caso de higiene das instalações, equipamentos e manipuladores, e mudança estrutural para o estabelecimento comportar seu volume produtivo com o apoio e fiscalização da CEAGESP.

Mais estudos sobre alimentação de rua são necessários para melhor caracterizar e propor melhorias para esse setor.

\section{REFERÊNCIAS}

1. Garcia RWD. Reflexos da globalização na cultura alimentar: considerações sobre as mudanças na alimentação urbana. Rev Nutr. 2003;16(4):483-92.

2. Oliveira ACG, Nogueira FAG, Zanão CFP, Souza CWO, Spoto MHF. Análise das Condições do Comércio de Caldo de Cana em Vias Públicas de Municípios Paulistas. Seg Alim Nutr. 2006;13(2):6-18.

3. Cardoso RCV, Souza EVA, Santos PQ. Unidades de alimentação e nutrição nos campi da Universidade Federal da Bahia: um estudo sob a perspectiva do alimento seguro. Rev Nutr. 2005;18(5):669-80.

4. Araújo WMC, Cardoso L. Qualidade dos alimentos comercializados no Distrito Federal no período de 1997-2001dissertação.. Brasillia: Universidade de Brasília; 2002.
5. Instituto Brasileiro de Geografia e Estatística. Pesquisa de Orçamentos Familiares 2008-2009: perfil das despesas no Brasil: indicadores selecionados / IBGE, Coordenação de Trabalho e Rendimento. Rio de Janeiro: IBGE, 2009.

6. Cavalli SB, Salay E. Gestão de pessoas em unidades produtoras de refeições comerciais e a segurança alimentar. Rev Nutr. 2007;20(6):657-67.

7. Silva Júnior EA. Manual de Controle Higiênico-Sanitário em Serviços de Alimentação. $6^{\mathrm{a}}$ ed. São Paulo: Editora Varela; 2008.

8. Ministério da Saúde homepage.. Doenças Transmitidas por Alimentos - Informações Técnicas acesso em 27 abr 2011.. Disponível em: http://portal.saude.gov.br/portal/ saude/profissional/visualizar texto.cfm?idtxt $=31758$

9. Boulos MEMS. Segurança alimentar: uma preocupação questão de atualizar e viabilizar informação. Nutrição em Pauta. 1999;37:21-3.

10. Ribeiro-Furtini LL, Abreu LR. Utilização de APPCC na indústria de Alimentos. Ciênc Agrotec. 2006;30(2):358-63.

11. Silva EL, Menezes EM. Metodologia da pesquisa e elaboração de dissertação. $3^{\mathrm{a}}$ ed. rev. atual. Florianópolis: Laboratório de Ensino a Distância da UFSC; 2001.

12. Brasil. Agência Nacional de Vigilância Sanitária. Resolução RDC no 275, de 21 de Outubro de 2002. Dispõe sobre o Regulamento Técnico de Procedimentos Operacionais Padronizados aplicados aos Estabelecimentos Produtores/ Industrializadores de Alimentos e a Lista de Verificação das Boas Práticas de Fabricação em Estabelecimentos Produtores/Industrializadores de Alimentos. Diário Oficial da União, Brasília, 23 out. 2002. Seção 1, p. 126.

13. São Paulo. Centro de Vigilância Sanitária (CVS) da Secretaria de Estado de Saúde de São Paulo. Portaria CVS 6, de 10 de março de 1999. Regulamento técnico sobre os parâmetros e critérios para o controle higiênico-sanitário em estabelecimentos de alimentos acesso em 29 jun 2011.. Disponível em: http://www.cvs.saude.sp.gov.br/

14. São Paulo. Centro de Vigilância Sanitária (CVS) da Secretaria de Estado de Saúde de São Paulo. Portaria CVS 18, de 09 de setembro de 2008. Regulamento técnico sobre os parâmetros e critérios para o controle higiênico-sanitário em estabelecimentos de alimentos acesso em 29 jun 2011.. Disponível em: http://www.cvs.saude.sp.gov.br/ 
15. São Paulo. Secretaria Municipal de Saúde. Portaria no 1210, de 02 de agosto de 2006. Aprova o Regulamento Técnico de Boas Práticas, que estabelece os critérios e parâmetros para a produção/fabricação, importação, manipulação, fracionamento, armazenamento, distribuição, venda para o consumo final e transporte de alimentos e bebidas. acesso em 29 jun 2011. Disponível em: http://www3. prefeitura.sp.gov.br/

16. Messias GM, Tabai KC, Barbosa CG. Condições higiênicosanitárias: situação das lanchonetes do tipo fast food do Rio de Janeiro, RJ. Rev Univ Rural Série Ciências da Vida. 2007;27(1):48-58.

17. Hobbs B, Gilbert RJ. Higiene e toxicologia de los alimentos. $2^{a}$ ed. Zaragoza: Acribia; 1986.

18. Oliveira MMM, Brugnera DF, Mendonça AT, Piccoli RH. Condições higiênico-sanitárias de máquinas de moer carne, mãos de manipuladores e qualidade microbiológica da carne moída. Ciênc Agrotec. 2008;32(6):1893-98.

19. Mendes RA, Azeredo RMC, Coelho AIM, Oliveira SS, Coelho MSL. Contaminação ambiental por Bacillus cereus em unidade de alimentação e nutrição. Rev Nutr. 2004;17(2):255-61.

20. Campos MRH, Kipnis A, Andre MCDPB, Vieira CAS, Jayme LB, Santos PP et al. Caracterização fenotípica pelo antibiograma de cepas de Escherichia coli isoladas de manipuladores, de leite cru e de queijo "Minas Frescal" em um laticínio de Goiás, Brasil. Cienc Rural. 2006;36(4):122127.

21. Brasil. Ministério da Saúde. Agência Nacional de Vigilância Sanitária. Resolução RDC no 216, de 15 de setembro de 2004. Regulamento técnico de Boas Práticas para Serviços de Alimentação. Diário Oficial da União, Brasília, 16 set. 2004. Seção 1, p. 25.

22. Brasil. Secretaria de Segurança e Saúde no Trabalho. Portaria no 24, de 29 de dezembro de 1994. Norma Regulamentadora (NR), estabelece a obrigatoriedade de elaboração e implementação, por parte de todos os empregadores e instituições que admitam trabalhadores como empregados, do Programa de Controle Médico de Saúde Ocupacional - PCMSO acesso em 06 jul 2011.. Disponível em: http://www.mte.gov.br/legislacao/ portarias/1994/p 19941229 24.pdf
23. Manual ABERC de práticas de Elaboração e serviço de Refeições para Coletividades, $8^{a}$ ed. São Paulo: ABERC; 2003.

24. Rosa MS, Negreiros SRF, Seabra LMJ, Stamford TLM. Monitoramento de tempo e temperatura de distribuição de preparações à base de carnes em escolas municipais de Natal (RN), Brasil. Rev Nutr. 2008;21(1):21-8.

25. Lucca A, Torres EAFS. Condições de higiene de "cachorro-quente" comercializado em vias públicas. Rev Saúde Públ. 2002;36(3):350-2.

26. São Paulo. Centro de Vigilância Sanitária. Portaria no 09, de 16 de novembro de 2000. Norma técnica para empresas prestadoras de serviço em controle de vetores e pragas Urbanas acesso em 06 julho 2011.. Disponível em: http:// www.cvs.saude.sp.gov.br/busca legis.asp 
Apêndice. Check List utilizado na avaliação do estabelecimento.

Número do quiosque:

\section{A - IDENTIFICAÇÃO DA EMPRESA}

1. Razão social:

2. Nome fantasia:

3. Alvará/Licença sanitária: 4. Inscrição Estadual/Municipal:

5. CNPJ/CPF: 6. Fone: $\quad$ 7. Fax:

8. E-mail:

9. Endereço (Rua; Av.):

10. no:

12. Bairro:

13. Município:

11. Compl.:

16. Ramo de atividade:

18. Número de funcionários:

14. UF:

15. CEP:

20. Categoria de produtos

17. Produção mensal:

Descrição da categoria:

Descrição da categoria:

Descrição da categoria:

Descrição da categoria:

Descrição da categoria:

21. Responsável técnico:

22. Formação acadêmica:

23. Responsável legal/Proprietário do estabelecimento:

24. Motivo da inspeção:

( ) Solicitação de licença sanitária

( ) Comunicação do início de fabricação de produto dispensado da obrigatoriedade de registro

( ) Solicitação de registro

( ) Programas específicos de vigilância sanitária

( ) Verificação ou apuração de denúncia

( ) Inspeção programada

( ) Reinspeção

( ) Renovação de licença sanitária

( ) Renovação de registro

( ) Outros

\section{B - AVALIAÇÃ̃O}

19. Número de turnos:

\section{EDIFICAÇÃO E INSTALAÇÕES}

\section{1 ÁREA EXTERNA}

1.1.1 Área externa livre de focos de insalubridade, de objetos em desuso ou estranhos ao ambiente, de vetores e outros animais no pátio e vizinhança; de focos de poeira; de acúmulo de lixo nas imediações, de água estagnada, dentre outros.

1.1.2 Vias de acesso interno com superfície dura ou pavimentada, adequada ao trânsito sobre rodas, escoamento adequado e limpas.

\subsection{ACESSO}

1.2.1 Direto, não comum a outros usos (habitação).

\section{3 ÁREA INTERNA}

1.3.1 Área interna livre de objetos em desuso ou estranhos ao ambiente.

\subsection{PISO}

1.4.1 Material que permite fácil e apropriada higienização (liso, resistente, drenados com declive, impermeável e outros). 
1.4.2 Em adequado estado de conservação (livre de defeitos, rachaduras, trincas, buracos e outros).

1.4.3 Sistema de drenagem dimensionado adequadamente, sem acúmulo de resíduos. Drenos, ralos sifonados e grelhas colocados em locais adequados de forma a facilitar o escoamento e proteger contra a entrada de baratas, roedores, etc.

\subsection{TETOS}

1.5.1 Acabamento liso, sem cor clara, impermeável, de fácil limpeza e, quando for o caso, desinfecção. 1.5.2 Em adequado estado de conservação (livre de trincas, rachaduras, umidade, bolor, descascamentos e outros).

\subsection{PAREDES E DIVISÓRIAS}

1.6.1 Acabamento liso, impermeável e de fácil higienização até uma altura adequada para todas as operações. De cor clara.

1.6.2 Em adequado estado de conservação (livres de falhas, rachaduras, umidade, descascamento e outros).

1.6.3 Existência de ângulos abaulados entre as paredes e o piso e entre as paredes e o teto.

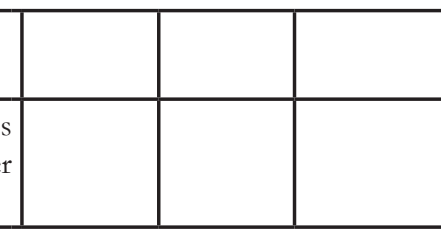

\subsection{PORTAS}

1.7.1 Com superfície lisa, de fácil higienização, ajustadas aos batentes, sem falhas de revestimento.

1.7.2 Portas externas com fechamento automático (mola, sistema eletrônico ou outro) e com barreiras adequadas para impedir a entrada de vetores e outros animais (telas milimétricas ou outro sistema).

1.7.3 Em adequado estado de conservação (livres de falhas, rachaduras, umidade, descascamento e outros).

\subsection{JANELAS E OUTRAS ABERTURAS}

1.8.1 Com superfície lisa, de fácil higienização, ajustadas aos batentes, sem falhas de revestimento.

1.8.2 Existência de proteção contra insetos e roedores (telas milimétricas ou outro sistema).

1.8.3 Em adequado estado de conservação (livres de falhas, rachaduras, umidade, descascamento e outros).

\subsection{ESCADAS, ELEVADORES DE SERVIÇO, MONTACARGAS E ESTRUTURAS AUXILIARES}

1.9.1 Construídos, localizados e utilizados de forma a não serem fontes de contaminação.

1.9.2 De material apropriado, resistente, liso e impermeável, em adequado estado de conservação.

\subsection{INSTALAÇÕES SANITÁRIAS E VESTIÁRIOS PARA OS MANIPULADORES}

1.10.1 Quando localizados isolados da área de produção, acesso realizado por passagens cobertas e calçadas.

1.10.2 Independentes para cada sexo (conforme legislação específica), identificados e de uso exclusivo para manipuladores de alimentos.

1.10.3 Instalações sanitárias com vasos sanitários; mictórios e lavatórios íntegros e em proporção adequada ao número de empregados (conforme legislação específica). 
1.10.4 Instalações sanitárias servidas de água corrente, dotadas preferencialmente de torneira com acionamento automático e conectadas à rede de esgoto ou fossa séptica.

1.10.5 Ausência de comunicação direta (incluindo sistema de exaustão) com a área de trabalho e de refeições.

1.10.6 Portas com fechamento automático (mola, sistema eletrônico ou outro).

1.10.7 Pisos e paredes adequadas e apresentando satisfatório estado de conservação.

1.10.8 Iluminação e ventilação adequadas.

1.10.9 Instalações sanitárias dotadas de produtos destinados à higiene pessoal: papel higiênico, sabonete líquido inodoro antisséptico ou sabonete líquido inodoro e antisséptico, toalhas de papel não reciclado para as mãos ou outro sistema higiênico e seguro para secagem.

1.10.10 Presença de lixeiras com tampas e com acinamento não manual.

1.10.11 Coleta frequente do lixo.

1.10.12 Presença de avisos com os procedimentos para lavagem das mãos.

1.10.13 Vestiários com área compatível e armários individuais para todos os manipuladores.

1.10.14 Duchas ou chuveiros em número suficiente (conforme legislação específica), com água fria ou com água quente e fria.

1.10.15 Apresentam-se organizados e em adequado estado de conservação.

\subsection{INSTALAÇÕES SANITÁRIAS PARA VISITANTES E OUTROS}

1.11.1 Instaladas totalmente independentes da área de produção e higienizados.

\subsection{LAVATÓRIOS NA ÁREA DE PRODUÇÃO}

1.12.1 Existência de lavatórios na área de manipulação com água corrente, dotados preferencialmente de torneira com acionamento automático, em posições adequadas em relação ao fluxo de produção e serviço e em número suficiente de modo a atender toda a área de produção.

1.12.2 Lavatórios em condições de higiene, dotados de sabonete líquido inodoro antisséptico ou sabonete líquido inodoro e antisséptico, toalhas de papel não reciclado ou outro sistema higiênico e seguro de secagem e coletor de papel acionados sem contato manual.

\subsection{ILUMINAÇÃO E INSTALAÇÃO ELÉTRICA}

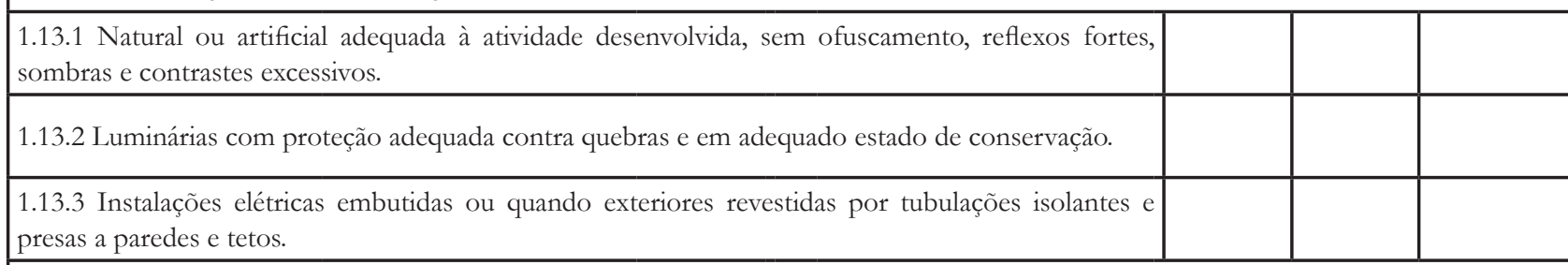

\subsection{VENTILAÇÃO E CLIMATIZAÇÃO}

1.14.1 Ventilação e circulação de ar capazes de garantir o conforto térmico e o ambiente livre de fungos, fumaça, pós, partículas em suspensão e condensação de vapores sem causar danos à produção.

1.14.2 Ventilação artificial por meio de equipamento(s) higienizado(s) e com manutenção adequada ao tipo de equipamento.

1.14.3 Ambientes climatizados artificialmente com filtros adequados.

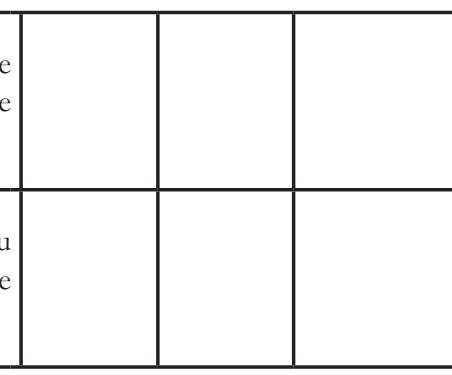


1.14.4 Existência de registro periódico dos procedimentos de limpeza e manutenção dos componentes do sistema de climatização (conforme legislação específica) afixado em local visível.

1.14.5 Sistema de exaustão e/ou insuflamento com troca de ar capaz de prevenir contaminações.

1.14.6 Sistema de exaustão e/ou insuflamento dotados de filtros adequados.

1.14.7 Captação e direção da corrente de ar não seguem a direção da área contaminada para área limpa.

\subsection{HIGIENIZAÇÃO DAS INSTALAÇÕES}

1.15.1 Existência de um responsável pela operação de higienização comprovadamente capacitado.

1.15.2 Frequência de higienização das instalações adequada.

1.15.3 Existência de registro da higienização.

1.15.4 Produtos de higienização regularizados pelo Ministério da Saúde.

1.15.5 Disponibilidade dos produtos de higienização necessários à realização da operação.

1.15.6 A diluição dos produtos de higienização, tempo de contato e modo de uso/aplicação obedecem às instruções recomendadas pelo fabricante.

1.15.7 Produtos de higienização identificados e guardados em local adequado.

1.15.8 Disponibilidade e adequação dos utensílios (escovas, esponjas, etc.) necessários à realização da operação. Em bom estado de conservação.

1.15.9 Higienização adequada.

\subsection{CONTROLE INTEGRADO DE VETORES E PRAGAS URBANAS}

1.16.1 Ausência de vetores e pragas urbanas ou qualquer evidência de sua presença como fezes, ninhos e outros.

1.16.2 Adoção de medidas preventivas e corretivas com o objetivo de impedir a atração, o abrigo, o acesso e/ou proliferação de vetores e pragas urbanas.

1.16.3 Em caso de adoção de controle químico, existência de comprovante de execução do serviço expedido por empresa especializada.

\subsection{ABASTECIMENTO DE ÁGUA}

1.17.1 Sistema de abastecimento ligado à rede pública.

1.17.2 Sistema de captação própria, protegido, revestido e distante de fonte de contaminação.

1.17.3 Reservatório de água acessível com instalação hidráulica com volume, pressão e temperatura adequados, dotado de tampas, em satisfatória condição de uso, livre de vazamentos, infiltrações e descascamentos.

1.17.4 Existência de responsável comprovadamente capacitado para a higienização do reservatório da água.

1.17.5 Apropriada frequência de higienização do reservatório de água.

1.17.6 Existência de registro da higienização do reservatório de água ou comprovante de execução de serviço em caso de terceirização.

1.17.7 Encanamento em estado satisfatório e ausência de infiltrações e interconexões, evitando conexão cruzada entre água potável e não potável.

1.17.8 Existência de planilha de registro da troca periódica do elemento filtrante. 
1.17.9 Potabilidade da água atestada por meio de laudos laboratoriais, com adequada periodicidade, assinados por técnico responsável pela análise ou expedidos por empresa terceirizada.

1.17.10 Disponibilidade de reagentes e equipamentos necessários à análise da potabilidade de água realizadas no estabelecimento.

1.17.11 Controle de potabilidade realizado por técnico comprovadamente capacitado.

1.17.12 Gelo produzido com água potável, fabricado, manipulado e estocado sob condições sanitárias satisfatórias, quando destinado a entrar em contato com alimento ou superfície que entre em contato com alimento.

1.17.13 Vapor gerado a partir de água potável quando utilizado em contato com o alimento ou superfície que entre em contato com o alimento.

\subsection{MANEJO DOS RESÍDUOS}

1.18.1 Recipientes para coleta de resíduos no interior do estabelecimento de fácil higienização e transporte, devidamente identificados e higienizados constantemente; uso de sacos de lixo apropriados. Quando necessário, recipientes tampados com acionamento não manual.

1.18.2 Retirada frequente dos resíduos da área de processamento, evitando focos de contaminação.

1.18.3 Existência de área adequada para estocagem dos resíduos.

\begin{tabular}{|l|l|l|}
\hline & & \\
\hline & & \\
\hline & & \\
\hline & & \\
\hline & & \\
\hline
\end{tabular}

\subsection{ESGOTAMENTO SANITÁRIO}

1.19.1 Fossas, esgoto conectado à rede pública, caixas de gordura em adequado estado de conservação e funcionamento.

\subsection{LAYOUT}

1.20.1 Layout adequado ao processo produtivo: número, capacidade e distribuição das dependências de acordo com o ramo de atividade, volume de produção e expedição.

1.20.2 Áreas para recepção e depósito de matéria-prima, ingredientes e embalagens distintas das áreas de produção, armazenamento e expedição de produto final.

\section{OBSERVAÇÕES:}

\section{EQUIPAMENTOS, MÓVEIS E UTENSÍLIOS}

\subsection{EQUIPAMENTOS}

2.1.1 Equipamentos da linha de produção com desenho e número adequado ao ramo.

2.1.2 Dispostos de forma a permitir fácil acesso e higienização adequada.

2.1.3 Superfícies em contato com alimentos lisas, íntegras, impermeáveis, resistentes à corrosão, de fácil higienização e de material não contaminante.

2.1.4 Em adequado estado de conservação e funcionamento.

2.1.5 Equipamentos de conservação dos alimentos (refrigeradores, congeladores, câmaras frigoríficas e outros), bem como os destinados ao processamento térmico, com medidor de temperatura localizado em local apropriado e em adequado funcionamento.

2.1.6 Existência de planilhas de registro da temperatura, conservadas durante período adequado.

2.1.7 Existência de registros que comprovem que os equipamentos e maquinários passam por manutenção preventiva.

2.1.8 Existência de registros que comprovem a calibração dos instrumentos e equipamentos de medição ou comprovante da execução do serviço quando a calibração for realizada por empresas terceirizadas. 


\subsection{MÓVEIS (MESAS, BANCADAS, VITRINES, ESTANTES)}

2.2.1 Em número suficiente, de material apropriado, resistentes, impermeáveis; em adequado estado de conservação, com superfícies íntegras.

2.2.2 Com desenho que permita uma fácil higienização (lisos, sem rugosidades e frestas).

\subsection{UTENSÍLIOS}

2.3.1 Material não contaminante, resistentes à corrosão, de tamanho e forma que permitam fácil higienização: em adequado estado de conservação e em número suficiente e apropriado ao tipo de operação utilizada.

2.3.2 Armazenados em local apropriado, de forma organizada e protegidos contra a contaminação.

\subsection{HIGIENIZAÇÃO DOS EQUIPAMENTOS E MAQUINÁRIOS E DOS MÓVEIS E UTENSÍLIOS}

2.4.1 Existência de um responsável pela operação de higienização comprovadamente capacitado.

2.4.2 Frequência de higienização adequada.

2.4.3 Existência de registro da higienização.

2.4.4 Produtos de higienização regularizados pelo Ministério da Saúde.

2.4.5 Disponibilidade dos produtos de higienização necessários à realização da operação.

2.4.6 Diluição dos produtos de higienização, tempo de contato e modo de uso/aplicação obedecem às instruções recomendadas pelo fabricante.

2.4.7 Produtos de higienização identificados e guardados em local adequado.

2.4.8 Disponibilidade e adequação dos utensílios necessários à realização da operação. Em bom estado de conservação.

2.4.9 Adequada higienização.

\section{OBSERVAÇÕES:}

\section{MANIPULADORES}

\subsection{VESTUÁRIO}

3.1.1 Utilização de uniforme de trabalho de cor clara, adequado à atividade e exclusivo para área de produção.

3.1.2 Limpos e em adequado estado de conservação.

3.1.3 Asseio pessoal: boa apresentação, asseio corporal, mãos limpas, unhas curtas, sem esmalte, sem adornos (anéis, pulseiras, brincos, etc.); manipuladores barbeados, com os cabelos protegidos.

\subsection{HÁBITOS HIGIÊNICOS}

3.2.1 Lavagem cuidadosa das mãos antes da manipulação de alimentos, principalmente após qualquer interrupção e depois do uso de sanitários.

3.2.2 Manipuladores não espirram sobre os alimentos, não cospem, não tossem, não fumam, não manipulam dinheiro ou não praticam outros atos que possam contaminar o alimento.

3.2.3 Cartazes de orientação aos manipuladores sobre a correta lavagem das mãos e demais hábitos de higiene, afixados em locais apropriados.

\begin{tabular}{|l|l|l|l|}
\hline & & & \\
\hline & & & \\
\hline & & & \\
\hline
\end{tabular}




\subsection{ESTADO DE SAÚDE}

3.3.1 Ausência de afecções cutâneas, feridas e supurações; ausência de sintomas e infecções respiratórias, gastrointestinais e oculares.

\subsection{PROGRAMA DE CONTROLE DE SAÚDE}

\begin{tabular}{|l|l|l|l|}
\hline 3.4.1 Existência de supervisão periódica do estado de saúde dos manipuladores. & & & \\
\hline 3.4.2 Existência de registro dos exames realizados. & & & \\
\hline
\end{tabular}

\subsection{EQUIPAMENTO DE PROTEÇÃO INDIVIDUAL}

3.5.1 Utilização de Equipamento de Proteção Individual.

\subsection{PROGRAMA DE CAPACITAÇÃO DOS MANIPULADORES E SUPERVISÃO}

3.6.1 Existência de programa de capacitação adequado e contínuo relacionado à higiene pessoal e à manipulação dos alimentos.

3.6.2 Existência de registros dessas capacitações.

3.6.3 Existência de supervisão da higiene pessoal e manipulação dos alimentos.

3.6.4 Existência de supervisor comprovadamente capacitado.

OBSERVAÇÕES:

\begin{tabular}{|l|l|l|l|}
\hline & & & \\
& & & \\
\hline & & & \\
\hline & & & \\
\hline
\end{tabular}

\section{PRODUÇÃO E TRANSPORTE DO ALIMENTO}

\subsection{MATÉRIA-PRIMA, INGREDIENTES E EMBALAGENS}

4.1.1 Operações de recepção da matéria-prima, ingredientes e embalagens são realizadas em local protegido e isolado da área de processamento.

4.1.2 Matérias-primas, ingredientes e embalagens inspecionados na recepção.

4.1.3 Existência de planilhas de controle na recepção (temperatura e características sensoriais, condições de transporte e outros).

4.1.4 Matérias-primas e ingredientes aguardando liberação e aqueles aprovados estão devidamente identificados.

4.1.5 Matérias-primas, ingredientes e embalagens reprovados no controle efetuado na recepção são devolvidos imediatamente ou identificados e armazenados em local separado.

4.1.6 Rótulos da matéria-prima e ingredientes atendem à legislação.

4.1.7 Critérios estabelecidos para a seleção das matérias-primas são baseados na segurança do alimento.

4.1.8 Armazenamento em local adequado e organizado; sobre estrados distantes do piso, ou sobre paletes, bem conservados e limpos, ou sobre outro sistema aprovado, afastados das paredes e distantes do teto de forma que permita apropriada higienização, iluminação e circulação de ar.

4.1.9 Uso das matérias-primas, ingredientes e embalagens respeita a ordem de entrada dos mesmos, sendo observado o prazo de validade.

4.1.10 Acondicionamento adequado das embalagens a serem utilizadas.

4.1.11 Rede de frio adequada ao volume e aos diferentes tipos de matérias-primas e ingredientes.

\subsection{FLUXO DE PRODUÇÃO}


4.2.1 Locais para pré-preparo (“área suja”) isolados da área de preparo por barreira física ou técnica.

4.2.2 Controle da circulação e acesso do pessoal.

4.2.3 Conservação adequada de materiais destinados ao reprocessamento.

4.2.4 Ordenado, linear e sem cruzamento.

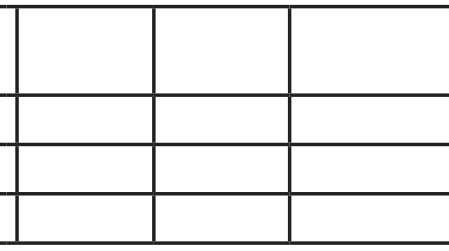

\subsection{ROTULAGEM E ARMAZENAMENTO DO PRODUTO-FINAL}

4.3.1 Dizeres de rotulagem com identificação visível e de acordo com a legislação vigente.

4.3.2 Produto final acondicionado em embalagens adequadas e íntegras.

4.3.3 Alimentos armazenados separados por tipo ou grupo, sobre estrados distantes do piso, ou sobre paletes, bem conservados e limpos ou sobre outro sistema aprovado, afastados das paredes e distantes do teto de forma a permitir apropriada higienização, iluminação e circulação de ar.

4.3.4 Ausência de material estranho, estragado ou tóxico.

4.3.5 Armazenamento em local limpo e conservado.

4.3.6 Controle adequado e existência de planilha de registro de temperatura, para ambientes com controle térmico.

4.3.7 Rede de frio adequada ao volume e aos diferentes tipos de alimentos.

4.3.8 Produtos avariados, com prazo de validade vencido, devolvidos ou recolhidos do mercado devidamente identificados e armazenados em local separado e de forma organizada.

4.3.9 Produtos finais aguardando resultado analítico ou em quarentena e aqueles aprovados devidamente identificados.

\subsection{CONTROLE DE QUALIDADE DO PRODUTO FINAL}

4.4.1 Existência de controle de qualidade do produto final.

4.4.2 Existência de programa de amostragem para análise laboratorial do produto final.

4.4.3 Existência de laudo laboratorial atestando o controle de qualidade do produto final, assinado pelo técnico da empresa responsável pela análise ou expedido por empresa terceirizada.

4.4.4 Existência de equipamentos e materiais necessários para análise do produto final realizadas no estabelecimento.

\subsection{TRANSPORTE DO PRODUTO FINAL}

4.5.1 Produto transportado na temperatura especificada no rótulo.

4.5.2 Veículo limpo, com cobertura para proteção de carga. Ausência de vetores e pragas urbanas ou qualquer evidência de sua presença como fezes, ninhos e outros.

4.5.3 Transporte mantém a integridade do produto.

4.5.4 Veículo não transporta outras cargas que comprometam a segurança do produto.

4.5.5 Presença de equipamento para controle de temperatura quando se transporta alimentos que necessitam de condições especiais de conservação.

\section{OBSERVAÇÕES:}

\section{DOCUMENTAÇÃO}

\subsection{MANUAL DE BOAS PRÁTICAS DE FABRICAÇÃO}

5.1.1 Operações executadas no estabelecimento estão de acordo com o Manual de Boas Práticas de Fabricação.

\subsection{PROCEDIMENTOS OPERACIONAIS PADRONIZADOS (POP)}




\subsubsection{HIGIENIZAÇÃO DAS INSTALAÇÕES, EQUIPAMENTOS E UTENSÍLIOS}

5.2.1.1 Existência de POP estabelecido para este item.

5.2.1.2 POP descrito está sendo cumprido.

5.2.2 Controle de potabilidade da água

5.2.2.1 Existência de POP estabelecido para controle de potabilidade da água.

5.2.2.2 POP descrito está sendo cumprido.

5.2.3 Higiene e saúde dos manipuladores

5.2.3.1 Existência de POP estabelecido para este item.

5.2.3.2 POP descrito está sendo cumprido.

5.2.4 Manejo dos resíduos

5.2.4.1 Existência de POP estabelecido para este item.

5.2.4.2 O POP descrito está sendo cumprido.

5.2.5 Manutenção preventiva e calibração de equipamentos.

5.2.5.1 Existência de POP estabelecido para este item.

5.2.5.2 O POP descrito está sendo cumprido.

5.2.6 Controle integrado de vetores e pragas urbanas

5.2.6.1 Existência de POP estabelecido para este item.

5.2.6.2 O POP descrito está sendo cumprido.

5.2.7 Seleção das matérias-primas, ingredientes e embalagens

5.2.7.1 Existência de POP estabelecido para este item.

5.2.7.2 O POP descrito está sendo cumprido.

\section{RECEBIMENTO}

6.1 Existe cadastro dos fornecedores?

$6.2 \mathrm{O}$ quiosque realiza visita técnica à seus fornecedores?

$6.3 \mathrm{O}$ local de recebimento garante a segurança do produto?

(área

protegida de chuva, sol, poeira, livre de materiais ou equipamentos inservíveis, de forma a garantir a segurança do produto)

6.4 O produto recebido é avaliado qualitativa e quantitativamente?

validade, lista de ingredientes, conteúdo líquido e no de registro no órgão oficial, quando for o caso)

6.5 Verifica nome e endereço do fabricante, fracionador, distribuidor e importador?

6.6 A temperatura é anotada em planilha no momento do recebimento?

\section{AMAZENAMENTO (PRODUTOS NÃO PERECÍVEIS)}

7.1 Os alimentos são separados por categoria?

7.2 Os alimentos estão dispostos longe do piso, à $40 \mathrm{~cm}$ das paredes e à $60 \mathrm{~cm}$ do forro?

7.3 Ambiente livre de entulho e material tóxico?

7.4 Temperatura e ventilação adequadas?

7.5 Todo material de higiene e limpeza ou qualquer outro material químico está separado dos alimentos?

7.6 Embalagens íntegras com identificação visível?

7.7 É utilizado o sistema Primeiro que Entra Primeiro que Sai (PVPS)?

7.8 Produtos destinados a devolução ou descarte estão em local apropriado?

\section{ARMAZENAMENTO (PERECÍVEIS)}

8.1 Possui equipamentos de refrigeração ou congelamento que permitam visualizar a temperatura interna pelo lado externo e sensor de temperatura na parte mais quente? 
8.2 Equipamentos de refrigeração se mantém ligados $24 \mathrm{~h}$ ?

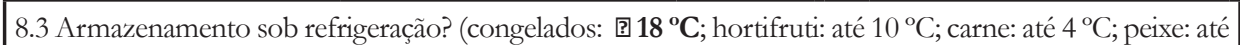
$\left.2{ }^{\circ} \mathrm{C}\right)$

\section{PRÉ- PREPARO}

\subsection{Fluxo linear?}

9.2 Isolado da área de preparo dos produtos já selecionados?

9.3 Embalagens são higienizadas antes de serem abertas?

9.4 Ocorre a seleção, lavagem, desinfecção e enxágue dos alimentos de maneira correta?

9.5 O dessalgue das carnes ocorre sob condições seguras?

sob refrigeração até $10^{\circ} \mathrm{C}$ ou fervura)

$9.6 \mathrm{O}$ descongelamento é feito abaixo de $5^{\circ} \mathbf{C}$ ou no microondas, quando o alimento for submetido à imediata cocção?

9.7 O fracionamento ocorre em área própria?

9.8 O fracionamento ocorre com utensílios próprios?

\begin{tabular}{|l|l|l|l|}
\hline & & & \\
\hline
\end{tabular}

\section{PREPARO}

10.1 A área de preparo permite fluxo adequado evitando contaminação cruzada?

10.2 Há lavatórios, exclusivos para lavagem das mãos dotados de sabonete antisséptico e papel toalha não reciclado, em locais de fácil acesso?

\section{EMBALAGEM, DISTRIBUIÇÃO E CONSUMO}

11.1Alimentos não utilizados imediatamente são embalados e datados?

11.2 Os alimentos estão devidamente protegidos contra poeira, pragas urbanas, saneantes, cosméticos, produtos de limpeza, de higiene ou demais produtos tóxicos?

11.3 São comercializados apenas produtos que não apresentem embalagens: rasgadas, furadas, latas amassadas, com ferrugem ou estufadas, bem como aquelas que apresentem sujidades que possam alterar a qualidade e integridade do produto?

11.4 Produtos perecíveis expostos à venda são conservados: congelados à ? $18^{\circ} \mathbf{C}$, ou refrigerados (hortifruti e outros a até $10^{\circ} \mathrm{C} /$ carne a até $4^{\circ} \mathrm{C} /$ peixe a até $2^{\circ} \mathrm{C}$ ), em temperatura ambiente de acordo com as propriedades intrínsecas do alimento ou de acordo com recomendação do fabricante?

11.5 A área de consumação possui os mesmos critérios de higienização da área de preparo?

$11.6 \mathrm{O}$ balcão térmico está limpo com água tratada e limpa, trocada diariamente, e mantido à temperatura de $80^{\circ} \mathrm{C}$ a $90^{\circ} \mathrm{C}$ ?

11.7 Os pratos prontos e alimentos perecíveis quentes expostos para consumo, em distribuição ou espera estão acima de $60^{\circ} \mathrm{C}$ por um período máximo de $6 \mathrm{~h}$, ou abaixo de $60^{\circ} \mathrm{C}$ por um período máximo de 1 h? 11.8 Os pratos prontos e alimentos perecíveis frios que dependem somente da temperatura para a sua conservação estão abaixo de $10^{\circ} \mathrm{C}$ por um periodo máximo de $4 \mathrm{~h}$, ou entre $10^{\circ} \mathrm{C}$ e $21{ }^{\circ} \mathrm{C}$ por um periodo máximo de $2 \mathrm{~h}$ ?

11.9 Ornamentos e plantas estão dispostos de forma a não contaminar os alimentos uso de adubo orgânico, fora do fluxo de ar ou de alimentos, nem sobre os balcões de distribuição)? 11.10 Os ventiladores do refeitório estão limpos e dispostos de forma que o fluxo de ar não vá em direção aos ornamentos, plantas ou alimentos?

\begin{tabular}{|l|l|l|l|}
\hline & & \\
\hline & & & \\
\hline
\end{tabular}

\begin{tabular}{|l|l|l|}
\hline & & \\
\hline & & \\
\hline & & \\
\hline & & \\
\hline & & \\
\hline
\end{tabular}




\section{C - CLASSIFICAÇÃO DO ESTABELECIMENTO}

( ) GRUPO 1 - 76 a $100 \%$ de atendimento dos itens

( ) GRUPO 2 - 51 a $75 \%$ de atendimento dos itens

( ) GRUPO 3-26 a 50\% de atendimento dos itens

( ) GRUPO $4-0$ a $25 \%$ de atendimento dos itens

\section{D - RESPONSÁVEIS PELA INSPEÇÃO}

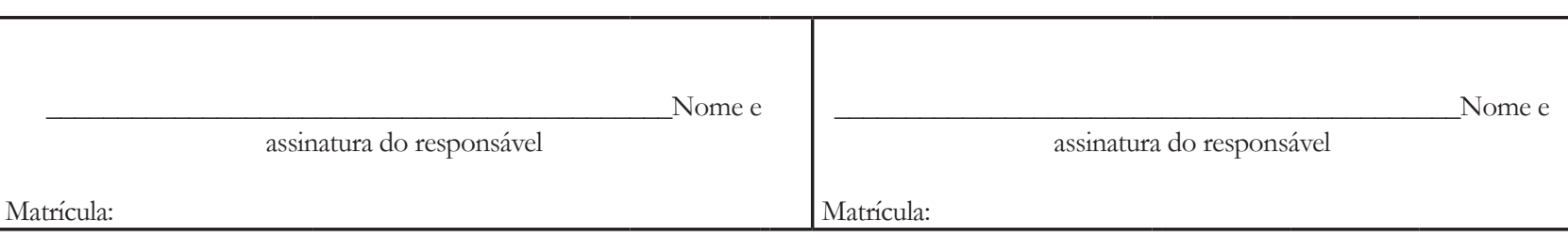

E - RESPONSÁVEL PELA EMPRESA

Nome e assinatura do responsável pelo estabelecimento

Local:

Data: $\ldots 1 \ldots 1$

$*$ NA = Não se aplica. 